\title{
The clinical epidemiology: contribution to others health undergraduate courses
}

Faculdade de Medicina de Ribeirão Preto - USP

The clinical pratice may be understood as a set of procedures which envelops the application of the inductive and deductive reasoning for the health prevention and recuperation. In a comprehensive view, the operational feature is an interdisciplinary action, going beyond (but not overlooking) the set of specific knowledges of medical formation.

The conjugation of semiological elements with those of socio-economic and cultural nature is implicit in the several phases of clinical pratice and/or the clinical aproaches of research (etiologic, prognostic, intervention and diagnostic studies). These points to the need for the clinical epidemiologic reasoning since the most initial phases of the undergraduate courses in the health areas.

In order to know the non-physician professionals motivation related to the inclusion of disciplines or specfic modules of Clinical Epidemiology in Undergraduate or Gradua- te courses it was made a survey with the professors from the University of São Paulo at Ribeirão Preto - College of Nursing.

The information was collected by a questionaire between the months of february and march, 1995, answered by each one of the professors $50 \%$ of them responded.

The results showed that despite the recognition related to the theme importance and the interest in including a specific discipline or modules of Clinical Epidemiology in the course of this Institution there were some controversy involving the "Clinical Epidemiology" meaning. There was specifically some resistance in accepting such an adjective for Epidemiology.

It was concluded that it is very propitious to promote some discussion with those professionals in order to aproach the discipline contents and to set up the means to apply the Clinical Epidemiology in the context of a Nursing College. 